\title{
La ciudad como espacio habitado y fuente de socialización*
}

\author{
The City as Space for Living and Source of Socialization \\ A cidade como espaço habitado e fonte de socialização
}

Recibido el 25 de noviembre de 2016. Aceptado el 30 de marzo de 2017

\author{
Erika Tatiana Ayala García** \\ Colombia
}

Para citar este artículo:

Ayala García, Erika Tatiana (junio, 2017). La ciudad como espacio habitado y fuente de socialización. Ánfora, 24(42),

189 - 216. Universidad Autónoma de Manizales. ISSN 0121-6538.

\section{Resumen}

Objetivos: comprender el papel del espacio público en la construcción físico-vivencial de la ciudad y en la experiencia social del ser humano. Metodología: se aplicó revisión documental interdisciplinar que siguió las etapas de investigación, sistematización y exposición. Para recopilar información sobre la noción del espacio público, se acudió a fuentes primarias como libros, artículos, tesis y trabajos de investigación que incluyeran categorías de estudio como espacio público, ciudad, construcción social, memoria e identidad. Resultados: se encontró que el espacio público es componente esencial en la configuración de la ciudad; a través del espacio público el ser humano puede potenciar su experiencia a partir de la relación con sus pares y el entorno. Conclusiones: en el

\footnotetext{
*Este artículo se deriva del segundo capítulo "El derecho a la ciudad: Entre lo construido y lo cotidiano", de la Tesis Doctoral en desarrollo La construcción del concepto de espacio público a través de la experiencia cotidiana de los niños y las personas mayores. Estudio interdisciplinar entre la arquitectura y las ciencias sociales. Universidad Politécnica de Cataluña, España. Tesis Doctoral en curso iniciada en el año 2012.

** Magíster. Arquitecta. Profesora de la Universidad Francisco de Paula Santander de Cúcuta. Directora del Grupo de Investigación Taller de Arquitectura y Dinámicas del Territorio TAR_GET /UFPS. Correo electrónico: erikatatianaayala@ufps.edu.co
} 
espacio público se produce el intercambio colectivo, la socialización y el anonimato; en él la persona genera lazos con sus pares y con el entorno, favoreciendo el arraigo de conceptos como el sentido de pertenencia y lugar. Por lo tanto, su planificación y desarrollo deben realizarse a partir de trabajos interdisciplinares que permitan proyectar la experiencia del ser humano.

Palabras clave: Espacio urbano; Ciudadanía; Identidad; Pertenencia.

\section{Abstract}

Objective: to understand the role of public space in the physical construction of the city and in the experiential and social experience of human beings. Methodology: interdisciplinary literature review that followed the stages of investigation, systematization and exposure was applied. To gather information on the notion of public space, we went to primary sources such as books, articles, theses and research papers to include categories of study as public space, city, social construction, memory and identity. Results: it was found that public space is an essential component in shaping the city; through public space humans can enhance their experience from the relationship with peers and the environment. Conclusions: collective sharing, socialization and anonymity occurs in public space; in it, the person generates ties with his/her peers and with the environment, favoring the entrenchment of concepts such as sense of belonging and place. Therefore, planning and development must be made from interdisciplinary project work that allows the experience of being human.

Keywords: Urban space; Citizenship; Identity; Membership.

\section{Resumo}

Objetivo: compreender o papel do espaço público na construção físico-vivencial da cidade e na experiência social do ser humano. Metodologia: aplicou-se a revisão documental interdisciplinar que seguiu as fases de investigação, sistematização e exposição. Para reunir informações sobre a noção do espaço público, acudiu-se a fontes primárias, tais como livros, artigos, teses e trabalhos de pesquisa onde se incluíram categorias de estudo como espaço público, cidade, construção social, memória e identidade. Resultados: encontrou-seque oespaço públicoéumcomponenteessencial na formação da cidade; através do espaço público o ser humano pode melhorar a experiência do relacionamento com os colegas e com o ambiente. Conclusões: no espaço público se produz o intercâmbio coletivo, a socialização e o anonimato; neste a pessoa gera vínculos 
com seus pares e com o meio ambiente, favorecendo a consolidação de conceitos como o sentimento de pertença e de lugar. Portanto, o planejamento e o desenvolvimento devem ser feitos baseados em trabalhos Inter disciplinais que permitam projetar a experiência do ser humano.

Palavras-chave: Espaço urbano; Cidadania; Identidade; pertença. 


\section{Introducción}

La ciudad es el mayor escenario de transformación del espacio habitado y vivencial en el que se desenvuelve el ser humano; es el lugar en el que la persona puede "ser o estar", debido a que la estructura y configuración física de la ciudad satisface las necesidades sociales, fisiológicas, de seguridad, de autoestima y autorrealización establecidas como intrínsecas dentro del desarrollo del ser social (Maslow, Sthepen y Gary, 1998); además, configura un espacio simbólico común y fluctuante, compuesto por una red de vías de comunicación, historias y flujos, que diariamente se reconstruye y autorregula.

Desde esta perspectiva, la idea de ciudad constituye una definición polisémica compleja que a lo largo de los años, y desde la academia, se ha desarrollado segmentadamente-a partir de la heterogeneidad que cada rama del conocimiento le atribuye; una noción de ciudad busca establecer diversas concepciones que dejan al descubierto la necesidad de indagar y reflexionar el espacio físico construido, a partir de posturas y líneas de pensamiento interdisciplinares que favorezcan una mirada y un entendimiento más complejo del concepto de ciudad.

Por lo tanto, este trabajo tiene como objetivo establecer el papel del espacio público dentro de la construcción físico vivencial de la ciudad y la experiencia social que desarrolla el ser humano dentro del mismo; esto, por medio del establecimiento de la configuración física y social del espacio público, el reconocimiento del papel del espacio público en la construcción física y social del espacio, la descripción de las experiencias sociales del ser humano dentro del espacio público y la identificación de las tipologías del espacio público, especialmente en la plaza.

La postura que acompaña y precede el concepto de ciudad desde la perspectiva urbana se enmarca, inicialmente, en los aspectos físicos, tangibles y/o cuantificables, que la describen como un asentamiento humano de elevada densidad poblacional, con elementos de infraestructura para suplir los servicios de educación, salud y esparcimiento de una sociedad (Sjoberg, 1965; Boisier, 2006). Tal teoría, es respaldada por Hall (1996) quien menciona que para Le Corbusier la ciudad es un espacio funcional a través del cual el ser humano satisface las necesidades de vivir, trabajar, desarrollar cuerpo y mente.

Es decir, se plantean las bases de una ciudad contemporánea definida por la contraposición de un ambiente natural y un espacio artificial altamente estandarizado y procesado, que en palabras Mumford (1968) se presenta como 
un pensamiento que se enfoca en la eficiencia del proceso, pero que carece de la comprensión de la importancia de la función social de la ciudad; esto configura un adoctrinamiento urbanístico expuesto repetidamente en el CIAM, en el que se cuestionaba el significado y re-direccionaba la naciente idea de ciudad, fruto de la Revolución Industrial.

Este discurso, con el paso de los años, se convirtió en epicentro de múltiples debates académicos en los que autores como Hall (1996) manifiestan su postura en torno a la idea de ciudad planteada por Le Corbusier; al respecto se afirma que el desarrollo de la ciudad debe ser fruto de una planificación justificada y del estudio consciente de las condiciones, físicas, sociales y culturales y no de la puesta en marcha de manifiestos urbanos que puntualicen soluciones generales para la planificación y construcción de ciudades e imaginarios ideales, que difieren de la realidad que acompaña y determina las necesidades de cada espacio.

De igual forma, surgen estudios y planteamientos como el de Lynch (1960), quien a través de un código común de lectura de lo urbano, describe la ciudad como un espacio organizado, simbólico y poético, que le permite al habitante desarrollar vínculos con su entorno inmediato; vínculos que van más allá de la necesidad, descripción o utilización de la estructura física de la misma, ya que, por el contrario, se apela a los lazos, significado y valor que los habitantes manifiestan en relación con su entorno inmediato. Esto, genera la elaboración de imágenes mentales que facilitan el reconocimiento y estudio de la ciudad y favorece el diagnóstico de la realidad física y social, así como sus posibles necesidades de transformación; según Ontañon (2004), se establece la imagen de una ciudad "deseable" y bien formada que gracias a la aprehensión sensorial por parte del ciudadano, incitaría a la simplificación y profundización de los entornos, estableciendo pautas de continuidad y lecturas urbanas menos segregadas.

Al respecto, Augé (1999) construye un discurso en el que se analiza la ciudad bajo una perspectiva social e individual que la define como un espacio antropológico en el que lo construido tiene un sentido para quienes lo habitan, lo viven, o lo observan; se configura así una relación entre lugar, identidad e historia, a partir de la cual el ser humano establece vínculos con el espacio y con sus pares. Desde este enfoque, sin embargo, la vivencia y construcción individual analizada por Augé apela a la generación de los "no-lugares", describiéndolos como espacios de tránsito que no favorecen la socialización y carecen de un vínculo identitario que, debido a que su enfoque conceptual, se encuentra enmarcado en la sobremodernidad. Es decir, la excesiva proliferación de espacios, acontecimientos e información que promueven la individualidad y se 
opone al enfoque del lugar antropológico, estableciendo espacios de recorrido, de corta estancia, frecuencia de uso moderada y no interacción.

Por tal razón, a partir del reconocimiento de esta línea de pensamiento transversal se puede establecer que la ciudad no es sólo un espacio de elementos físicos que albergan a una población, cuya única función radica en satisfacer las necesidades de sus habitantes. Al contrario, la ciudad da cuenta del carácter vivencial y experimental que surge de la cotidianidad, de la puesta en marcha de las actividades desarrolladas en los espacios de uso colectivo y de la autodeterminación de sus pobladores; la ciudad es el eje fundamental, a través del cual se conjugan elementos que otorgan sentido a la vida en comunidad (Borja, 2012) y que se desarrolla como un espacio que responde a un modelo de organización económico, político, social, cultural y morfológico (Llavería, 2006).

Con base en lo anterior, Ayala y Rodríguez (2014) señalan cómo a partir de 1969, Henry Lefebvre, en "El derecho a la ciudad", analiza la urbe desde un enfoque psicológico, político y sociológico, centrado en la vida cotidiana y la experiencia vital que manifiesta el ser humano en relación con su entorno inmediato (Costes, 2012). Se genera así, por primera vez, un debate sobre la noción de lo urbano, en el que se percibe la ciudad como un espacio de consumo físico y mercantil donde los habitantes reivindican y transforman la materialidad de las calles, los parques y las plazas, como lugares de encuentro y construcción de la vida comunitaria; en tal debate, además se sustentaba el derecho fundamental de los ciudadanos al disfrute de los espacios de uso colectivo, compuestos por las diferencias, las contradicciones, las ideas, los pensamientos y las opiniones propias de la vida urbana (Urzúa, 2012).

Desde este punto de vista, diez años después Henry Lefebvre, en "De lo urbano a lo Rural”, plantea un interesante discurso de reflexión y cuestionamiento acerca de los enfoques y las perspectivas que ramas como la sociología, la arquitectura, el urbanismo y la geografía han desarrollado en torno al tema de la ciudad; así se sentaron las bases de un discurso que apunta a la construcción mancomunada de la misma, a partir de la identificación de los aportes que cada línea del conocimiento genera con respecto a la idea de ciudad.

Sumado a la percepción de autores como Llorente (2014), quien asegura que:

La idea de ciudad representa un cerco teórico que limita un territorio de ideas que fluyen dentro de la tradición urbana, ideas complejas que se extienden desde los orígenes de nuestra civilización hacia el presente y debaten conceptos que van 
desde la forma de ser de los que habitan la ciudad, sus distintas identidades (...) y más allá hasta las complejas estructuras materiales y físicas que han creado el uso, los espacios y edificios diseñados por el azar, la tradición el arte o la razón (p. 78).

En tal contexto, el objetivo general de este artículo consiste en comprender el papel del espacio público en la construcción físico vivencial de la ciudad y la experiencia social que manifiesta el ser humano dentro del mismo. Para ello, se parte de objetivos específicos como: 1. Reflexionar en torno a la Configuración física y social del espacio, por medio del cual se pretende identificar las unidades de actuación que organizan y acompañan la ciudad; 2. Analizar el papel del espacio público en la construcción física y social del espacio, objetivo que describe el desarrollo de la ciudad a partir del siglo XIX, favoreciendo el reconocimiento del perfil físico y sociológico del espacio público con respecto a su incidencia en la ciudad; 3. Entender la noción de transeúnte, memoria e identidad, objetivo que gira en torno a la experiencia social que desarrolla el ser humano dentro del espacio público, favoreciendo la construcción de imágenes mentales tanto individuales como colectivas que lo estructuran como miembro activo de la sociedad; 4. Explicar las Zonas recreativas de uso público que permiten establecer las tipologías del espacio público, haciendo un énfasis especial en las plazas y en su historia.

De esta manera, en la presente revisión documental se evidencia el papel que ejerce el espacio público con respecto a la planificación y el desarrollo de la ciudad, se resalta la importancia de analizarlo interdisciplinarmente desde un enfoque físico y social que genere planteamientos morfológicos que enriquezcan la experiencia vital de los habitantes que cotidianamente lo apropian. El desarrollo de este tipo de estudios concebidos desde la parte documental, o de planificación urbana, pueden generar un alto impacto en la población con productos que respondan y satisfagan las necesidades de la ciudad y la población en general.

\section{Metodología}

La metodología se desarrolló a partir de una revisión documental, seguida de la sistematización y selección de los recursos obtenidos para su posterior análisis. La búsqueda de la información se realizó a través de material bibliográfico compuesto por libros, Tesis Doctorales y artículos de bases de datos bibliográficas como Scopus, Mendeley, Science Direct y Dialnet. 
Con base en ese entorno documental internacional, se recabó información referida a la noción de espacio público que se presenta desde diferentes ramas del conocimiento como la arquitectura, la sociología, la psicología, la antropología y la geografía humana. Se estableció, entonces, un marco teórico interdisciplinar que promoviera una mirada holística sobre la importancia que ejerce el espacio público en el desarrollo de las ciudades, desde una perspectiva física y vivencial. Las categorías que orientaron este estudio corresponden a espacio público, ciudad, construcción social, memoria e identidad.

\section{Resultados}

Los resultados se presentan conforme a los objetivos descritos con anterioridad por medio de los siguientes apartados, En el primero se describe la configuración física y social del espacio. En el segundo se reflexiona sobre el papel del espacio público en la construcción física y social del espacio. El tercero aborda la reivindicación del ciudadano, la memoria y la identidad y el último apartado se centra en las Zonas recreativas de uso público.

\section{Configuración física y social del espacio}

La composición y funcionamiento de la ciudad pueden ser observados y analizados, desde una perspectiva funcional o vivencial. La configuración física que la acompaña y precede gira en torno al establecimiento, desarrollo y función de unidades específicas como el barrio, el espacio público y las vías de comunicación; esto establece el patrón de orientación geográfica y el asentamiento de los ciudadanos por medio de la articulación de cada una de sus partes, que conforman un entramado compuesto por llenos, vacíos, y condicionamientos que establecen diferencias papables del territorio, desde una perspectiva funcional y morfológica.

Sumado a esto, se enmarca la visión antropológica y el concepto de topogénesis introducido por Muntañola i Thornberg (2000), quien desde la semiología y la arquitectura del territorio, analiza profundamente el lugar estudiando el funcionamiento y la articulación de sus partes; dota así a la arquitectura de significado y emotividad, convirtiéndola en un proceso por el cual los habitantes generan vínculos emocionales y vivenciales con su entorno inmediato, desarrollando una recordación más allá de la identificación física del espacio que se configura en procesos en los que intervienen la memoria, la identidad y el arraigo. 
En consecuencia, las unidades de actuación que acompañan y organizan la ciudad se establecen a partir de referentes como el barrio, unidad socioeconómica compuesta y regida por relaciones comunitarias en las que la ciudad desarrolla su sentido funcional. El barrio se convierte en un referente urbano de características singulares y delimitación territorial, contenedor de la vida social que hace parte de la cotidianidad y el desarrollo del ser social del individuo (Rapoport, 1978); con ello, se establece, según Gravano (2013), un espacio físico compuesto por un mundo de significados de carga simbólica transferidos generacionalmente y que determinan valores de diferenciación e identidad que estructuran y organizan el territorio. Esto, a la vez, suscita una imagen específica con atributos apropiados por los residentes, generando un vínculo irrompible e irremplazable que gira en torno a la sinergia entre los aspectos construidos y vivenciales que hacen parte del espacio en el que se desarrolla.

En este sentido, Serrano (2005) analiza el significado que autores como Merlin y Choay (1988) le atribuyen a la definición de barrio, quienes lo describen como una fracción del territorio con fisionomía y características propias que le otorgan un grado de singularidad en relación con otras fracciones habitacionales que, sumado a la construcción cultural o la representación espacial, generan lazos afectivos; a través de estos vínculos se constituyen procesos sociales, culturales, económicos y políticos a pequeña escala, estableciendo patrones físicos con identidades y características propias que pueden llegar a estructurar o desestructurar el territorio (Lefebvre, 1969).

Con lo anterior, se demarcan puntos de vista que develan los componentes sociales, morfológicos y/o funcionales propios de la configuración del barrio; según Jiménez Mantilla (1998), se generan límites espaciales que establecen el paisaje urbano basados en la organización espacial, equipamientos, jerarquías físicas, estructurales y sociales que, que definen los rasgos característicos de los vecindarios, describiéndolos como espacios cambiantes, dinámicos, con autonomía y gobernabilidad (Castells, 1985). De esta manera, el barrio se determina como la unidad básica del urbanismo y mediante el cual se reconocen, analizan y diagnostican fracciones de la ciudad, de acuerdo con la identificación de nociones de una composición física y estructural potencializada por los procesos de encuentro e intercambio propios del ser social. Hecho que conlleva la necesidad de abordar el carácter social del espacio público. 


\section{El papel del espacio público en la construcción social y física del espacio}

El espacio público es el medio por el cual se reconoce la historia de la ciudad, debido a que expresa la materialización de las relaciones entre sus habitantes, el poder y la ciudadanía; se conforman con mediante los lugares colectivos como plazas, parques y calles, definidos como partes de encuentro ciudadano (Borja y Muxí, 2001). De esta forma, la ciudad es entendida como un organismo, un sistema de redes compuesto por espacios de uso colectivo y apropiación constante, que permiten y fomentan el paseo y el encuentro, ordenando la ciudad y otorgándole un sentido.

Desde esta perspectiva, Gamboa (2003) reconstruye un recorrido sobre la evolución de la ciudad y los cambios que la noción de espacio público ha sufrido con el paso del tiempo; narra, por ejemplo, cómo en el siglo XIX el desarrollo del espacio urbano se configuró a través del ascenso de la burguesía al poder político, los procesos de industrialización, y el exagerado y desorganizado crecimiento urbano que trajo como consecuencia la necesidad de nuevos equipamientos de orden civil, social y cultural; ello, a partir de cambios que estaban orientados al intercambio y al ocio que configuraron el naciente espacio público como una red de intercambio colectivo que se difunde en el territorio, se nutre de lo cotidiano y otorga a la ciudad un nuevo código de lectura coherente a las nuevas formas urbanas de socialización. Asimismo, la ciudad se abre por primera vez a la totalidad de sus habitantes desarrollando un sistema de espacio púbico concreto y controlado, caracterizado por la implementación de parques, jardines públicos, bulevares y monumentos.

Gamboa (2003), además anota cómo el movimiento moderno reorganiza racional y funcionalmente la ciudad, con base en referentes como la ciudad verde y la ciudad jardín; con ello desplaza del protagonismo al peatón para dar paso al automóvil, símbolo de modernidad, movimiento y progreso, que va de la mano del crecimiento acelerado de las urbes y da al ciudadano una autonomía de movilidad que repercute en la creación de nuevas vías que se desligan paulatinamente del espacio colectivo de la ciudad. Dicho referente cambia progresivamente en los años 60, gracias a pensadores como Jacobs, 1973; Lynch, 2014 y Rossi, 1995, que evidencian una nueva percepción de la ciudad, entendiéndola como un conjunto de sistemas especializados a través de los cuales se puede reflexionar no sólo como una forma física, sino también como un sistema continuo de espacios colectivos que definen y enmarcan las cualidades y calidades urbanas. 
Desde su concepción polisémica, espacio público se define como un estadio físico y sociológico que tiene la capacidad de ser el lugar donde se produce la vida y el intercambio colectivo; simultáneamente, sin embargo, es el espacio que propicia el anonimato y el desencuentro. Borja y Muxí (2001) lo definen como una entidad cultural, política, social y simbólica que fomenta la relación y la identificación, como un espacio físico de animación urbana y expresión comunitaria que refleja la historia de la ciudad, a través del cual los habitantes materializan sus ideales; y éstos, sumados a la concepción de Rangel (2002) establece el espacio público como un lugar de diversificación e interacción en el que el ser humano tiene la posibilidad de expresarse y generar lazos, no sólo con sus pares sino con su entorno, mediante la puesta en marcha de actividades, ideas, nociones y sentimientos que generan conceptos como el sentido de pertenencia y de lugar (Ortiz i Guitart, 2003).

Bajo la anterior consideración, los espacios públicos son los encargados de albergar y congregar los usos, las aspiraciones y la diversidad cultural que caracteriza a la población y facilitan la promoción de nuevas formas de identidad para dar forma al tejido urbano (Aragall i Clavé, 2002), (Barnada, 2006). El espacio público, al ser el sitio en el que el ciudadano se integra a su comunidad, "habla" sobre el deseo colectivo, ya que en él se materializa la atmósfera de la vida urbana, se desarrollan historias individuales y colectivas y se presentan las congregaciones que hacen parte de los ciclos de aceptación o rechazo de los procesos sociales fruto de la cotidianidad de las masas.

Por tal razón, para Pérgolis y Moreno (2013), el espacio público se abstrae de su forma física para convertirse en un lugar simbólico, lleno de sentidos, a través del cual se producen procesos de comunicación estructurales y de reivindicación entre el arquitecto y los usuarios que hablan de acontecimientos y le otorgan una literatura de vida a los espacios, reafirmando que dichos espacios no sólo hacen referencia a la trama, la linealidad o la simetría de sus calles y plazas, sino que son los lugar de los paseos, de los eventos, el vitrineo y de las manifestaciones de poder.

En este sentido, Borja (2014) asegura que "sin espacio público el asentamiento humano masivo no es ciudad. No hay ciudadanía” (p.3) y recuerda que los espacios colectivos son los lugares para la relación, el encuentro, el desencuentro, el azar; son concebidos como espacios libres, heterogéneos y multifuncionales; espacios de poder económico y político, pero sobre todo cultural; en los espacios colectivos convergen los grupos que construyen memoria e identidad. Por tal razón, su estudio, planificación y desarrollo no debe centrarse en el quehacer de una rama 
específica sino en un enfoque interdisciplinar, tanto de las ciencias sociales como de la arquitectura, que busque comprender las diversas dinámicas y lógicas que hacen parte del proceso de configuración uso y apropiación del espacio físico y vivencial que acompaña la cotidianidad de las personas.

Desde la sociología y la geografía humana, autores como Duran (1998) y Wilson (1995) han reflexionado sobre la importancia que ejercen los espacios públicos en el desarrollo de la ciudad, describiéndolos como los lugares donde se fomenta la construcción social por excelencia, basada en procesos de diversificación e intercambio que promueven el desarrollo urbano y reafirman que la experiencia pública del ciudadano se puede generar sin un plan determinado, a partir del uso o la apropiación repetitiva y consciente de un lugar específico. Concepto que refuerza la idea de Neves (2014), para quien:

El espacio arquitectónico necesariamente es un elemento que aliado con otros como la luz, el color, el tiempo, construye un conjunto formal que adquiere significados no sólo para los arquitectos, sino también para los usuarios (...) siendo el espacio en este contexto un elemento fenomenológicamente presente comprendido y usado como indisociable de la forma y de los significados inherentes a esas formas que pueden consustanciar una dimensión poética del espacio, dentro de una perspectiva de afirmación (p. 255).

De acuerdo con lo anterior, se puede afirmar que la relación entre urbanismo, sociedad y arquitectura se nutre de espacios públicos como calles, plazas, parques y áreas verdes, representando y materializando los lugares de encuentro que fortalecen la identidad y diversidad del ambiente urbano (Páramo y Cuervo, 2006; Hernández Bonilla, 2008). Se compre, entonces, el espacio público no sólo como elemento residual que se abre paso entre las construcciones, sino como la institución social que constituye la dimensión más líquida e inestable de las dinámicas urbanas, a través de la cual circulan flujos como energías, personas, vehículos, información, recursos y servicios (Delgado, 2003).

Igualmente, las reflexiones de Buttimer (1976), Relph (1976), Massey (1995) y Rose (1995) plantean que el desarrollo, uso y caracterización del espacio público ha sufrido importantes variaciones con el paso del tiempo; resaltan cómo el enfoque geógrafo-humanista de los años sesenta -que tenía como epicentro el estudio y la reflexión de la vinculación afectiva y la experiencia de las personas en los entornos urbanos- da paso a la concepción planteada a partir de los años noventa, de pertenencia y sentido de lugar, logrando que la geografía humana analice cómo el espacio público a partir de su concepción abstracta se convierte en 
un lugar definido por la experiencia y la apropiación, consciente o inconsciente, de los individuos quienes lo humanizan y le otorgan significado.

Delgado (2007), utiliza una analogía en la que compara la actividad peatonal con una coreografía, argumentando que la danza se asemeja a la perfección del lenguaje y es el resultado de los intercambios que se producen en los espacios urbanos, describiéndola como una creación artística que utiliza al máximo las capacidades expresivas y las energías del cuerpo en un tiempo y espacio determinado, planteando un escenario a través del cual la danza al igual que el caminar por la ciudad describe la interacción que tienen las personas con su medio físico, espacial, con lo que los rodea y con lo que les permite tener contacto con los demás seres humanos.

Bajo este contexto, para Augoyard (1979) y Bertrand (1981) el caminar se convierte en una actividad tan importante como hablar; esto, porque tanto a través de la palabra como de los itinerarios, los recorridos y los encuentros casuales de los transeúntes se redescubre y redefine la ciudad. De esta forma los lugares por donde se transita se convierten en una geografía imaginaria compuesta por inclusiones, exclusiones, llenos y vacíos que colonizan el espacio provisionalmente; una geografía en la que acciones como observar, caminar, vivir y experimentar cotidianamente la ciudad, el barrio y las calles, reivindican al transeúnte como el principal protagonista del espacio público (Gelh y Gemzoe, 2002). Ello le confiere un nuevo significado a la vivencia espacial que, al convertir las calles en un entramado de rutas de paseo, le otorgan al espacio público un carácter social y de esparcimiento, que influye directamente en el fortalecimiento de la memoria y la construcción de la identidad del ciudadano.

\section{La reivindicación del ciudadano, la memoria y la identidad}

De acuerdo con lo anterior, el espacio colectivo de la ciudad es un escenario social, a través del cual la persona tiene la posibilidad de ser, estar, trascender y permanecer; esto favorece la construcción de una imagen mental individual y colectiva que se nutre de la vivencialidad espacial cotidiana, del azar, del encuentro y del desencuentro. Bajo este contexto, la ciudad, a través del espacio público, se convierte en multiplicadora de experiencias en las que el transeúnte reestructura y reorganiza constantemente su idea de la urbe, generando lazos, códigos e historias que estructuran y fortalecen su rol como miembro activo de una sociedad que apela al sentido y al derecho a la ciudad. 
Es necesario resaltar, entonces, que históricamente el espacio público ha generado la socialización y la expresión de los ciudadanos, por ser común y rico en vivencias, continuamente recorrido y fácilmente identificado (Rangel, 2002). Cotidianamente, calles, avenidas y plazas son apropiadas por los ciudadanos, que, a través de estos espacios comunican quiénes son, qué sienten, qué piensan, a qué aspiran. El espacio público se reafirma no como una entidad, sino como una representación que actúa como medio de identificación social y cultural que se forja y se nutre de la experiencia cotidiana de quienes la utilizan, generándoles la posibilidad de identificarse, recordar, guardar y percibir, dentro de su memoria activa y pasiva, imágenes, hechos, escenas, lugares y representaciones a través de las cuales puede identificarse con el pasado o el presente (Borja y Muxí, 2001) configurando así los espacios colectivos de la ciudad como significantes que denotan una dimensión existencial, emocional y cultural que promueve la identidad, el sentido de pertenencia y el arraigo.

Al respecto, Cosgrove y Jackson (1987) definen la cultura como el medio según el cual las personas tienen la capacidad de transformar fenómenos terrenales y comunes del mundo material a un mundo de símbolos, lleno de significados propios y valiosos; ello, permite afirmar que el valor cultural de una ciudad se configura en torno a su identidad, ya que los seres humanos desarrollan su cotidianidad estableciendo lazos físicos y afectivos con sus entornos físicos y sociales; hecho que plantea un estudio exhaustivo de la identidad a partir de elementos como el bienestar subjetivo y social (Valera y Pol, 1994) que establece la cultura como un elemento clave para analizar la percepción y apropiación de los seres humanos sobre los espacios.

Sánchez y Domínguez (2014), de su parte, afirman que el hecho de habitar no es ajeno al tema de la identidad, ya que la ciudad actual atraviesa un momento crítico de convivencia debido a los diversos conflictos sociales, los procesos de innovación tecnológica y la lucha interna por fomentar la búsqueda de alternativas sostenibles, amables y racionales en relación con la naturaleza. Desde esta perspectiva, la experiencia espacial y vivencial del ser humano se debate en torno a la voluntad de acercamiento o distanciamiento, catalogando los espacios que albergan una identidad como los más apreciados, representando así la valorización máxima del patrimonio (Hiernaux-Nicolas, 2014).

Lindón (2014) menciona que cuando el ser humano habita un lugar, tiene la posibilidad de manufacturarlo materialmente de acuerdo con su modo de vida, fijando historias y símbolos, pero sobre todo, otorgándole identidad y configurándolo como único y específico; este hecho, según Tajfel (1982), 
Thompson (1993) y Pedragosa (2014), describe la ciudad como el espacio en el que se consolidan lazos sociales, a partir de la construcción de un escenario narrativo y simbólico, de expresión cultural que se genera a través de la percepción de sus autores (Thompson, 1993). Por tal razón, el ser social desarrolla un sentido de pertenencia que se construye a través de la utilización de los espacios colectivos de la ciudad, a partir del uso de la memoria individual y colectiva que lo ubica histórica y espacialmente por medio de interacciones desarrolladas a partir de la existencia y la experiencia individual que contribuyen al reconocimiento de quiénes somos y el hecho del porqué somos así (Fenster, 2004).

A partir de los años 70 la geografía humana ha desarrollado interés en el enfoque que estudia la vinculación afectiva del ser humano en relación con su entorno. Para Mendoza y Bartolo (2012) los años 90 se configuran como el período fundamental en el que la arquitectura comienza a compartir conceptos analíticos derivados de la geografía humana, como el "sentido de lugar", por medio del cual se profundiza como un espacio abstracto y genérico puede llegar a adquirir un significado que a través de la acción y la experiencia cotidiana de los individuos, valoriza y reivindica la construcción de una identidad individual y colectiva. Esto, permite entender la ciudad como un espacio vivo desarrollado a través de una construcción histórica, social, comunitaria y cotidiana, que según la geógrafa inglesa Dooreen Massey (2012) influye en la forma como se desarrolla una sociedad y en la imagen que tiene de sí misma, debido a que el espacio físico se construye y nutre a partir de la interacción y las relaciones sociales, generando identidades parciales asociadas a la nación, la región y la ciudad.

Así pues, el espacio urbano se presenta como el medio a través del cual los habitantes tienen la posibilidad de formar su identidad y memoria, ya que en él se satisfacen necesidades personales y sociales, y se establece una identificación espacial y una conexión psicológica (Silva, 2006). De esta manera, el espacio se constituye como una imagen que se forma por medio de la percepción de los individuos. Así se crean espacios simbólicos compuestos por diferentes modos de vida, aspiraciones, utopías y creencias, que logran fortalecer tanto la identidad personal como social demarca la pertenencia a un determinado grupo o espacio con el que se identifican (Tajfel, 1982).

Por tal razón, la arquitectura, la sociología y la psicología han estudiado y enfocado estas inquietudes desde diferentes acepciones. Erickson (1974) estudia el concepto de identidad desde la psicología social a través de preguntas problematizadoras como ¿Quién soy? Y ¿Dónde estoy? Para Duran (1998), en 
tanto, el sentido de identidad nace de la interrelación entre el sujeto y el lugar que habita, entendiendo que el sentido de pertenencia -desde una perspectiva cultural-se manifiesta como un generador y alimentador social -colectivo- que potencia la identificación, el orgullo la lealtad y el compromiso por parte de la ciudadanía (Miller, 1997) (Pool, 1999), que establece la memoria del lugar y se presenta como un referente que contribuye a la creación del territorio, a través de la experimentación, la cotidianidad y la imaginación; se reivindica así un espacio colectivo representado en el lenguaje, el uso y la apropiación como elementos que fortalecen la identidad de lugares simbólicos donde se plasma la vida cotidiana.

Así mismo, Le Breton (2002), Toledo (2007) y Hurssel (2008) realizan importantes acotaciones en referencia a la relación entre el ser humano y su entorno, acuerdo con las experiencias sensibles, afectivas, valorativas y estéticas que forman parte de la vida cotidiana; de esto, se deriva información sobre la experiencia perceptiva y sensible del mundo, que favorece la comprensión del territorio desde una lógica sensible a través de un pensamiento crítico, resaltando que los territorios no sólo se configuran como espacios físicos construidos o de producción sino como lugares generadores de experiencia y arraigo. Por eso, es necesario reconocer la importancia de las plazas dentro del espacio público que conforma las ciudades, por medio del reconocimiento del papel que las mismas han jugado dentro de la historia.

\section{Zonas recreativas de uso público}

La recreación, el ocio y el disfrute son factores determinantes en del crecimiento físico e intelectual de los seres humanos. Por tal razón, en la planificación de la ciudad, los espacios públicos constituyen el medio material a través de los cuales la población, sin distinción alguna, puede acceder a zonas recreativas pasivas o activas, que contribuyen a la generación de la cultura urbana.

Con base en esto, Planeación Distrital de Bogotá (1993) establece como zonas recreativas de uso público las plazas, definiéndolas como el lugar público por excelencia que resulta de la agrupación de edificios en torno a un espacio libre con lectura unitaria, donde predominan los elementos arquitectónicos sobre los naturales; ofrece a los usuarios multiplicidad de opciones de uso, que dependen de su infraestructura, tradición, escala, dimensión, flexibilidad, mobiliario y tradición de apropiación colectiva. De la misma manera, establece la plazoleta como un espacio de menor escala donde se desarrollan relaciones próximas entre los edificios, el espacio público y los usuarios; seguidamente de los parques, 
descritos como espacios libres al interior de la ciudad, destinados a la recreación al aire libre y al contacto con la naturaleza y que hacen parte del sistema del espacio público y por lo tanto su escala está determinada por su dimensión y uso.

Para Campos (2011), la plaza representa el reconocimiento colectivo que habla de la aceptación de la pluralidad social, política y cultural presentes en la sociedad; es un patrimonio histórico y nacional, que genera experiencia y sustenta la relación del hombre con el entorno, fortalece el imaginario urbano-social del lugar, pues se trata de un elemento cargado de simbolismo e identificación ciudadana, que permite el desarrollo de múltiples actividades y usos como un elemento articulador y generador de la malla urbana (Bazant, 2010).

En ese orden de ideas, se requiere ahondar, históricamente, en la cosmovisión del diseño y función de la plaza con el fin de reflexionar en torno a su origen, diseño y distribución, destaca los acontecimientos más importantes que han rodeado el establecimiento del espacio público a partir de la conceptualización de la plaza. Sobre la noción de plaza, entonces, Martínez Caro y De las Rivas (1990) aseguran que es un lugar de encuentro y actividades se remontan a hace ya más de 8000 años en ciudades neolíticas en la Anatolia como Çatalhöyük; en éstas se disponían de plazas públicas para el intercambio de productos. Igualmente, en Egipto y Mesopotamia se edificaron plazas ceremoniales junto a grandes avenidas y salas hipóstilas para adorar a sus dioses.

Campos (2011) realiza también un recorrido que parte de la cultura griega, en la que la plaza pública se caracteriza por cumplir funciones políticas, religiosas y económicas; era el lugar de las transacciones comerciales. Su composición física gira en torno a un edificio para el culto de héroes y dioses, y un edificio para la asamblea que contenía las oficinas de los magistrados, los almacenes y el archivo, complementado por un espacio abierto y multifuncional dedicado a satisfacer la función económica. Para los romanos, la plaza pública se representaba a través del foro que se encontraba cerrado por pórticos y contenía los locales comerciales y la sede del senado, razón por la cual posteriormente se desarrolló una separación entre el foro civil y el foro del mercado ${ }^{1}$.

\footnotetext{
1 En las polis griegas la Acrópolis representaba la ciudad de los dioses y estaba configurada a partir de una plaza abierta sobre la colina donde se ubicaban los templos, mientras que la ciudad se desarrollaba en torno al Ágora considerada como el corazón de la vida urbana, siendo el lugar del encuentro ciudadano, comercial, intelectual o artístico, mientras que Roma Julio Cesar construyo un foro regular porticado rodeado de edificios públicos frente al templo de Júpiter configurando una gran plaza descubierta utilizada para grandes reuniones que se establece como el patrón a través del cual en el imperio posteriormente se proliferan los foros como espacios regulares cerrados dispuestos caprichosamente (Martínez y De las Rivas, 1990, pp. 43).
} 
Ahora, la ciudad medieval trae consigo cambios importantes soportados en la configuración del aprendizaje cotidiano, a través del cual las artes y los oficios se convierten en los principales protagonistas. Por tal razón, la morfología de la plaza parte del ensanchamiento de los espacios de circulación -rodeados por viviendas y comercio- en los que se desarrollaban las fiestas populares y carnavales. Este uso, difiere del propósito de la plaza en el Renacimiento; en tal época se instauró la creación de la ciudad ideal prevista de una plaza principal que actúa como epicentro y jerarquía máxima de una red de espacios públicos organizados y planificados. Se complementa este concepto de plaza durante el periodo Barroco, en el que, a través de las plazas, se buscó embellecer la ciudad y glorificar al régimen monárquico.

Posteriormente, el crecimiento acelerado de la población y la densificación del siglo XVIII -y después de una época caracterizada por la desorganización urbana y la precariedad e insalubridad de los espacios colectivos- se fomentó la proyección de espacios abiertos transformados en plazas ajardinadas. Con la visión de Napoleón III y el barón de Haussmann, en el siglo XIX, se crean lugares como en París, donde inició una serie de transformaciones urbanas en las cuales la ciudad se abrió a las vías de comunicación rápidas y estableció la plaza como un espacio abierto al público en general. Esta tendencia se fortalece a través del movimiento de arquitectura moderna liderado por Le Corbusier, para quien cada la ciudad debería manifestar una unidad natural, de manera que en cada barrio debería contar con una plaza o parque, cada ciudad con un parque metropolitano y cada región con un parque natural.

Según lo anterior, la arquitectura ha jugado un papel importante en la caracterización del espacio que ha acompañado el desarrollo de las ciudades, incluyendo la interacción manifiesta del ser humano con su entorno inmediato. Así, se establecieron las plazas públicas como lugares de encuentro e identificación con capacidad de estímulo de la integración cultural, la convivencia, la identificación simbólica y la expresión humana (Norberg-Shulz, 2000); simultáneamente, motivan la educación ambiental y el desarrollo social y favorecen una lectura de ciudad cargada de hechos urbanos significativos (Tricart y Killian, 1982).

A partir de los estudios de las escuelas alemanas y francesas, las ciudades empezaron a priorizar los temas derivados de estudios ambientales, estableciendo funciones a los espacios públicos enfocadas al desarrollo de la calidad espacial y la experiencia del habitante dentro de los espacios que hacen parte de su cotidianidad. De esta manera, Perahia (2007) destaca las funciones atribuidas al espacio público, resaltando que desde el ámbito social es el lugar que ofrece ocio, 
paseo, contemplación, contacto con la naturaleza, entre otros, y los caracteriza como indispensables para el desarrollo de los niños y el equilibrio de los adultos. Así mismo, asegura que desde el ámbito urbanístico y paisajístico se produce una discontinuidad entre la masa edificada que oxigena la malla urbana y establece nuevos puntos de encuentro ciudadano, sumado ello a la implementación de la vegetación a través de la cual se contribuye a regular el microclima urbano.

Los espacios públicos se convierten, pues, en componentes indispensables para la planeación y el desarrollo territorial y en puente de comunicación entre el espacio habitado y el ser humano. Esto, favorece la generación de condiciones que promueven la sociabilidad, el descanso físico y mental, la reflexión en torno a valores sociales y morales, el crecimiento espiritual, el fomento de nuevas amistades y la mejora del sentido de lugar². Por tal razón, Dos Anjos, Tavares y Baptista (2009) aseguran que una de las principales funciones de los espacios públicos es favorecer la recreación, entendiendo que el ser humano se encuentra en la constante búsqueda de alternativas que le permitan disfrutar el espacio en el que vive. Se logra así desarrollar un aprendizaje común de uso individual y/o colectivo, que sumado a la correcta planeación de factores como accesibilidad, cercanía a sistemas de transporte público y comercio, favorecen la comunicación con otras partes de la ciudad y el disfrute, el uso y la apropiación de los espacios colectivos de la ciudad.

Con base en esto, Pozueta (2008) destaca la importancia de una buena concepción y materialización del espacio público para el éxito del mismo; para ello, describe los efectos derivados del desarrollo de actividades urbanas al aire libre y su incidencia en factores como el sentimiento de bienestar, relajación, independencia y seguridad. Para este autor, desde un ámbito económico los espacios públicos inciden de manera positiva o negativa en el valor comercial de los edificios próximos, así como en la generación de recursos de administración; resalta casos de éxito en ciudades como Berlín, donde, en el año 2000, un área residencial podía llegar a incrementar su valor hasta en un $16 \%$ debido a su cercanía a espacios de juegos infantiles; o en Boston, donde el alquiler de las propiedades cercanas a espacios públicos se establecía en un 19\% más alto de su valor comercial con respecto a otras edificaciones además, se suman efectos colaterales que contribuyen al mejoramiento de los espacios urbanos, relacionados con actividades como limpieza de fachadas, mejoramiento de instalaciones y de mobiliario urbano, que favorecen la frecuencia de uso, apropiación y el

\footnotetext{
2 El uso y la apropiación constantes de los espacios y la infraestructura destinada para el disfrute o el ocio establecen una relación entre el sujeto -actor-y la experiencia vivida, recordando que las actividades de ocio y lúdicas se presentan como un derecho individual y social democrático (Carvalho Marcellino, 2007).
} 
sentimiento de seguridad de los ciudadanos en relación con los espacios públicos (Laing y Urguhart, 1997; Luther y Gruehnind, 2001; Philips, 2001).

Sobre los efectos sociales, Pozueta (2008) destaca que los espacios públicos bien diseñados y mantenidos incitan a la congregación y se convierten en lugares de encuentro que fomentan las relaciones sociales; promueven la integración de la comunidad mediante el arraigo, el sentido de lugar y el sentido de pertenencia; establecen el desarrollo de experiencias sociales en los espacios colectivos de la ciudad, que favorecen la cohesión y elevan la calidad de vida de los habitantes.

También sostiene Pozueta (2008) que los espacios públicos planificados y correctamente desarrollados fomentan la actividad física en la práctica de deportes como correr, caminar o jugar, entre otros; resalta que la correcta implementación de los espacios públicos dentro de la ciudad fomentan formas de movilidad más sostenibles que reducen el incide de accidentalidad; y recuerda además, que "el tráfico rodado erosiona el sentimiento de comunidad", fomentando la creación y utilización de espacios peatonales, la verificación en cuanto la materialidad espacial con respecto a la iluminación y el estado actual del mobiliario y las conexiones interiores del mismo, la organización y la arborización; recordando así que la excesiva presencia de automóviles es directamente proporcional a los accidentes, el ruido, la polución y la contaminación visual.

En síntesis, el escenario urbano es objeto de múltiples interrelaciones internas y externas; el espacio con adecuado manejo ambiental contribuye a la calidad de vida del lugar y favorece el embellecimiento, la recreación y la disminución de impactos ambientales derivados de la modernidad, como el ruido, mediante la ubicación de árboles, barreras topográficas y el diseño de vías de tráfico lento. También ayuda a la conservación de la fauna y de la flora y la calidad visual y paisajística del espacio público a través de la cual la imagen urbana incide directamente en el comportamiento de la sociedad (Red de desarrollo sostenible de Colombia, 2015).

\section{Conclusiones}

Se concluye que a partir de los años sesenta se despertó una conciencia no sólo crítica con respecto a la planificación y el reconocimiento de la ciudad y su espacio público como medio habitado, sino un interés por el estudio y la incidencia que ejerce la relación del ser humano con su entorno. Lynch (1960) y Lefebvre (1969) estiman que la ciudad se forja a partir de la experiencia cotidiana de los 
ciudadanos, por medio de la generación de vínculos intangibles que denotan lazos significativos que promueven el sentido de comunidad.

Por tal razón, se considera que dentro de la planificación urbana se deben reconocer las diferentes voces que a través de las fuentes teóricas interdisciplinares le apuestan a la construcción y planificación de la ciudad, por medio de enfoques que pueden llegar a establecer lecturas propias del territorio a través de las cuales el ciudadano se convierta en el medio para potencializar la memoria y la identidad.

Así mismo, sobre el papel del espacio público en la construcción social y física del espacio, se concluye que la historia de las ciudades se presenta como uno de los principales insumos que dan forma y contextualizan los periodos que han hecho parte de su estudio y desarrollo a lo largo del tiempo, presentándose como una huella latente que favorece el reconocimiento de los procesos que abordan el entendimiento de la ciudad tanto desde el ámbito morfológico como el vivencial.

Con respecto a la reivindicación del ciudadano, la memoria y la identidad, luego de revisar los aportes realizados por autores como Borja y Muxí (2001), Fenster (2004), Silva (2006) y Sánchez González y Domínguez (2014) la conclusión es que la ciudad y los espacios públicos son multiplicadores de experiencias por medio de las cuales los ciudadanos son reconocidos como miembros activos de la sociedad; debido a que a través del uso, la apropiación y la transformación de los espacios los ciudadanos tienen la posibilidad de expresarse y comunicarse, estableciendo experiencias cotidianas que reafirman que el espacio público promueve la identidad, el sentido de pertenencia y el arraigo.

Por tal razón, es necesario que desde las ramas del conocimiento provenientes de las ciencias sociales y humanas referenciadas en el presente artículo se reconozcan los términos, diseños y funciones que a lo largo del tiempo han acompañado la conceptualización, el diseño y el desarrollo del espacio público; esto, con el fin de comprender que su uso, utilización y transformación tanto espacial como vivencial son la respuesta de una ciudad vislumbrada como espacio habitado y como fuente de socialización que reivindica al ciudadano, promueve la memoria colectiva y fortalece la identidad.

Finalmente, se considera que las zonas recreativas de uso público favorecen el crecimiento intelectual y físico del ser humano, dejando en evidencia el importante papel que ha desarrollado la arquitectura en la caracterización y el desarrollo de las ciudades. Hecho desde el cual se resalta la postura de 
Pozueta (2008) para quien el éxito del espacio público se fundamenta a partir de su concepción y materialidad, mediante la satisfacción de factores como el sentimiento de bienestar, la relajación, la independencia y la seguridad; a través de los cuales se fortalecen las relaciones sociales, la cohesión y la calidad de vida de los habitantes.

Se concluye, finalmente, la importancia que ejerce el espacio público en la configuración de la ciudad y se recomienda realizar investigaciones interdisciplinares que favorezcan la comprensión y la optimización de las características tanto físicas como vivenciales del mismo. Asimismo, se entiende que el espacio público se presenta como un elemento esencial en la configuración de la ciudad; por eso, el espacio público es el escenario a través del cual el ser humano puede potencializar su experiencia vital a partir de la relación con sus pares y con el entorno, generando planos o imágenes mentales que refuerzan el reconocimiento espacial de la ciudad y fortalecen la experiencia vivida dentro de la misma.

\section{Referencias}

Aragall i Clavé, F. (2002). De la ciutat sense barreres de la ciutat per a tothom. Barcelona: Diputación de Barcelona.

Auge, M. (1999). Los no-lugares. Espacios del anonimato. Una antropología de la sobremodernidad. Barcelona: Gedisa.

Augoyard, J. F. (1979). Pas à pas: essai sur le cheminement quotidien en milieu urbain. Paris: Seuil.

Ayala, E. T. y Rodríguez, A. R. (2014). Aproximación al análisis del espacio fronterizo colombo-venezolano. La Parada como caso de estudio. Bitácora urbano territorial, 2(24), 31-41.

Barnada, J. (2006). Dotze ciutats els seus espais. Barcelona: UPC.

Bazant, J. (2010). Espacios urbanos, historia, teoria y diseño. México: Limusa.

Bertrand, M. J. (1981). La ciudad cotidiana. Madrid: Instituto de Estudios de Administración Local. 
Boisier, S. (2006). Algunas reflexiones para aproximarse al concepto de ciudad-región. Estudios Sociales, 14(28), 163-190.

Borja, J. (2014). Revolución urbana y derechos ciudadanos: Claves para interpretar las contradicciones de la ciudad actual. Barcelona: Universidad de Barcelona.

Borja, J., y Muxí, Z. (2001). Espacio Público: Ciudad y ciudadanía. Barcelona: Electa.

Buttimer, A. (1976). Grasping the Dynamism of Lifeworld. Annals of the Association of American Geographers, (66), 277-292.

Campos, G. I. (2011). El origen de la plaza pública en México: Usos y funciones sociales. Argumentos, 24(66).

Carvalho, N. (2007). Lazer e cultura. Alinea.

Castells, M. (1985). La cuestión urbana. Madrid: Siglo XXI.

Cosgrove, D. y Jakcson, P. (1978). New directions in cultural geography. Area, 19(9-1).

Costes, L. (2012). Del "derecho a la ciudad" de Henri Lefebvre a la universalidad de la urbanización moderna. Revista Urban Nso2(2), 89-100.

Delgado, M. (2003). Carrer, festa i revolta: els usos simbòlics de l'espai públic a Barcelona (1951-2000). Barcelona: Generalitat de Catalunya, Departament de Cultura.

Delgado, M. (2007). Sociedades movedizas, pasos hacia una antropología de las calles. Barcelona: Anagrama.

Dos Anjos, F. A., Tavares, L. J. y Baptista López, V. (2009). La organización del espacio público y privado en áreas central del sistema turístico. Estudios y perspectiva en turismo, $18(5)$.

Duran, M. d. (1998). La ciudad compartida. Conocimiento, afecto y uso. Madrid: Consejo superior de los colegios de Arquitectos de España.

Erikson, E. (1974). Identidad, juventud y crisis. Buenos Aires: Paidós. 
Fenster, T. (2004). The global city and the Holy city, narratives on knowlegde, planning and diversity. Londres: Pearson Education.

Gamboa, P. (2003). El sentido urbano del espacio público. Instituto de investigaciones en ciudad, hábitat y territorio, 1(7).

Gelh, J. y Gemzoe, L. (2002). Nuevos espacios urbanos. Barcelona, España: Gustavo Gili.

Gravano, A. (2013). Antropología de la ciudad. Buenos Aires, Argentina: Tandil.

Hall, P. (1996). Ciudades del mañana: Urbanismo del siglo XXI. Barcelona, España: Editorial Serbal.

Hernández, M. (2008). Procesos informales del espacio público en el hábitat popular. Bitácora urbano territorial, 13(2), 109-116.

Hiernaux, D. (2014). Identidades cosmopolitas en las sociedades posmodernas. En D. Sánchez y L. Domínguez, Identidad y espacio público. Ampliando ámbitos y prácticas (pp. 41-54). Barcelona, España: Gedisa.

Hurssel, E. (2008). Crisis de las ciencias europeas y la fenomenología transcendental. Buenos Aires, Argentina: Prometeo libros.

Jacobs, J. (1973). Muerte y vida en las grandes ciudades. Madrid, España: Península.

Jiménez, L. C. (1998). El barrio: lugar entre la ciudad y la vivienda. Series de ciudad y hábitat, 5.

Laing, R. y Urguhart, D. (1997). Stone cleaning and its effect om property market selling price. Journal of Property Research, (14), 329-336.

Lebreton, D. (2002). Antropología del cuerpo y la modernidad. Buenos Aires: Nueva visión.

Lefebvre, H. (1969). El derecho a la ciudad (Vols. 44 de Historia, ciencia y sociedad). Pensilvania: Universidad Estatal de Pensilvania.

Lindon, A. (2014). El habitar la ciudad, las redes topológicas del urbanita y la figura del transeúnte. En D. Sánchez y L. A. Domínguez. Identidad y es- 
pacio público: ampliando ámbitos y prácticas (pp. 55-76). Barcelona, España: Gedisa.

Luther, M. y Gruehnind, D. (2001). Putting a price on urban green spaces. Landscape desing (303), 23-25.

Lynch, K. (2014). La Imagen de la ciudad. Barcelona: Editorial Gustavo Gili Reprint.

Llavería, J. (2006). El arte de construir en diálogos urbanos confluencias entre arte y ciudad. I congreso internacional de arte y entorno, la ciudad sentida, arte, entorno y sensibilidad. Valencia: CIAE UPV.

Llorente, M. (2014). Topología del espacio urbano. Palabras, imágenes, experiencias que definen la ciudad. Madrid, España: Abada editores.

Martínez Caro, C. y De las Rivas, J. (1990). Arquitectura urbana: elementos de teoría $y$ diseño. Belisco.

Maslow, A., Sthepen, D. y Gary , H. (1998). Maslow on management. New York: John Wiley.

Massey, D. (1995). Space, place and gender. Cambrigde: Polity press.

Massey, D. (2012). Espacio, lugar y política en la coyuntura actual urbana, 7-12.

Mendoza, C. y Bartolo, D. (2012). Lugar, sentido de lugar y procesos migratorios. Migración internacional desde la periferia de la Ciudad de México. Documents d'Anàlisi Geogràfica, 58(1), 55-77.

Miller, D. (1997). Citizenship and national identity. Cambridge: Polity Press.

Mumford, L. (1968). The urban prospect: Essays. Universidad de Michigan: Harcourt, Brace \& World.

Muntañola, J. (2000). Topogenesis: Fundamentos de una nueva arquitectura. Barcelona: UPC. 
Neves, V. (2014). Los espacios públicos: vacíos con identidad. Lugares con poética. En D. Sánchez y L. A. Domínguez, Identidad y espacio público ampliando ámbitos y prácticas. Barcelona, España: Gedisa.

Ontañon, P. A. (2004). Los significados de la ciudad. Barcelona: Edicions de l'Escola Massana.

Ortiz i Guitart, A. (2003). Gènere, espais públics i construcció del sentit de pertinença a Barcelona (Els barris de Prosperitat, el Verdum i el Raval). Tesis doctoral. . Barcelona: Universidad Autonoma de Barcelona.

Paramo, P. y Cuervo, M. (2006). Historia social situada en el espacio público de Bogotá, desde su fundación hasta el siglo XIX. Bogotá: Universidad Pedagógica Nacional.

Pedragosa, P. (2014). Identidad y diferencia en la "ciudad genérica" y en la "ciudad histórica". Percepción y prácticas espaciales. En D. Sánchez y L. Domínguez, Identidad y espacio público: ampliando ámbitos y prácticas (pp. 215234). Barcelona, España: Gedisa.

Perahia, R. (2007). IX coloquio internacional de geo crítica "los problemas del mundo actual, soluciones y alternativas desde la geografía y las ciencias sociales". Las ciudades y su espacio público. Porto Alegre: Universidade Federal do Rio Grande do Sul.

Pergolis, J. C. y Moreno, D. (2013). Espacio público: narrativas y deseos. Nodo, $7(14)$.

Philips, P. (2001). The real estate impacts of urban parks. Economics Research Associated.

Planeación Distrital de Bogotá. (1993). Cartilla de espacio público. Bogotá: Alcaldía de Bogotá.

Pool, R. (1999). Nation and identity. Londres: Routledge.

Pozueta, J. (2008). El espacio público en la rehabilitación/regeneración urbana. Revista de urbanismo (18). 
Rangel, M. (2002). Los cien del espacio público para la vida sociocultural urbana. Venezuela: Universidad de los Andes.

Rapoport, A. (1978). Aspectos humanos de la forma urbana. Barcelona, España: Gustavo Gili.

Red de desarrollo sostenible de Colombia. (2015). Red de desarrollo sostenible de Colombia. Obtenido de

Relph, E. (1976). Place and Placelessness. Londres: Pion limited.

Rose, G. (1995). Place and identity: a sense of place. En D. Massey. A place in a word? Place, Culture and Globalization. Oxford: Oxford University Press.

Rossi, A. (1995). La arquitectura de la ciudad. Punto y linea. Barcelona, España: Gustavo Gili.

Sánchez, D., y Dominguez, L. A. (2014). Identidad y espacio público: Ampliando ambitos y prácticas. Barcelona, España: Gedisa.

Serrano, J. (2005). Reseña de "Dictionnaire de l'urbanisme et de l'aménagement" de Pierre Merlin y François Choay. Papeles de Geografía (41-42), 255-257.

Silva, A. (2006). Imaginarios Urbanos. Bogotá, Colombia: Arango Editores.

Sjoberg, G. (1965). Preindustrial city: Past and present. New York: Freepress.

Tajfel, H. (1982). Social identity and intergroups relations. Cambridge: Cambridge University Press.

Thompson, J. (1993). Ideología y cultura moderna. Teoria Critica Social en la era de la comunicación de las masas. México: Universidad Autonoma de Xochimilco.

Toledo, U. (2007). Realidades múltiples y mundos sociales: Introducción a la socio fenomenología. Cinta de Moebio Revista Electrónica de Epistemología de las Ciencias Sociales (30), 242-280.

Tricart, J. y Killian, J. (1982). La ecografía y la ordenación del medio natural. Barcelona: Anagrama. 
Urzúa, V. (2012). El espacio público y el derecho a excluir. Athenea digital, 12(1), 159-168.

Valera, S. y Pol, E. (1994). El concepto de indentidad social urbana: Una aproximación entre la psicología social y la psicología ambiental. Anuario de psicología (62), 5-24.

Wilson, E. (1995). The rhetoric of urban space. New Left Review, (2009), 140-160. 